\title{
On the Interstellar Ethics in the Movie Avatar
}

\author{
Manli Wang \\ Xi'an Peihua University, Xi'an 710125, China
}

Keywords: Avatar; interstellar ethics; interstellar colonization; cultural conflict.

\begin{abstract}
Avatar is a classic old work often discussed from the perspectives of ecological ethics, ecological crisis, environmental pollution and anti-war, etc. Many researchers have paid special attention to the concept of anthropocentrism and the overall concept of ecology in this work. In this paper, the author analyzed the interstellar ethics contained in this movie by comparing Earth with Pandora, Earth people and Na'vi people and through the transformation of the hero's ethical values. Pandora is a utopian spiritual paradise. "Ethics" should not be confined to human society, but should also be extended to non-human creatures and other creatures on other planets, because harmonious coexistence and mutual care are the fundamental means to overcome the harm of anthropocentrism to Earth.
\end{abstract}

\section{Introduction}

The word "ethics" has extremely rich meaning. In general, "ethics" refers specifically to a set of rules in human society that maintains interpersonal relationships and social order. Ethics includes human emotions, wills, outlook on life and values and it is a behavioral guiding principle to guide individuals in society. "Interstellar ethics" can be seen as the rules and norms of conduct for the equal and peaceful coexistence between Earth people and living entities on other planets. The movie Avatar fictionalized a future ethical relationship between humans on Earth and "humans" on the planet called Pandora.

\section{Complete Opposition to the Living Environment: Earth and Pandora}

The movie Avatar began with a dark tone. Earth in the $22^{\text {nd }}$ century was a reinforced-concrete forest. Pedestrians wore masks or mouth shads, with offish expressions. In a dirty and inferior pub, a man brutally beat a woman. Earth suffered energy crunch, becoming a place dominated by jungle justice. Jake, a retired "patriotic" soldier sitting in a wheelchair, drowned his sorrows by drinks and watched the world with cold eyes. For him, life was a nightmare. Afterwards, Jack was taken away by strangers to replace the brother Tommy who had been killed to perform a scientific experiment on a planet called Pandora.

Jack initially entered Avatar for pure scientific experiments. However, the cutting-edge scientific research in the United States generally cannot be separated the huge economic support of chaebols and even involved in the common intervention of the military, and it inevitably carries the ideology of centralism in the United States. Colonel Quaritch, Jake's supervisor, was a typical fanatic supporter and admirer of capitalist industry and technological civilization. He came to Pandora for the rare ore Unobtanium, a walnut-sized of which was worth 20 million US dollars. Huge economic interests had induced human greed. Na'vi Princess Neytiri had a younger sister. They were the best students of the scientist Dr. Grace Augustine and were intellectual "surprising" girls. Because of dissatisfaction with human deforestation and the destruction of bulldozers, Neytiri's sister was finally brutally killed by the US military in front of Neytiri. Grace had always stressed that "wealth is around us, so we Na'vi people defend it". Unfortunately, the military and the chaebols could not and also were unwilling to understand what Grace said about "wealth". After the outbreak of the war, plundering everything seemed to be justified and they utilized wars to legalize aggression and plunder.

The word "Pandora" is derived from ancient Greek mythology. Zeus, the Lord God, gave his sister-in-law Pandora a box as a wedding gift in order to punish the prophet Prometheus. Pandora was 
very curious. One day, she opened the box when her husband was not at home, and then, diseases, disasters, plagues, etc. spewed out. When she closed the box, "Hope" was left in the box. "Hope" is always accompanied by pain and suffering. As long as one embraces the hopes, he/she will eventually have the courage to live a new life. In a sense, the Pandora's Box is a symbol of hope.

Pandora was a magical place, huge and dense plants with colorful leaves and swaying plants with delicious juicy fruits. The pterosaurs of the primitive era soared in the sky; beasts with hammer-shaped head hunted fiercely on other creatures; black wolves came out to feed at night and the six-legged horses with tentacles ran. Plants glowed at night like streetlights standing by the edge of the grass and seeds of the sacred tree fluttered like fireflies. The mountain range suspending in the air led to a beautiful and mysterious place. The creatures living on Pandora were "Na'vi" whose appearance was not great different from that of the earthman. The difference was that Na'vi people were tall and fit, with well-proportioned body. They had four fingers and huge ears, with long tail, blue skin, golden eyes like cats and sharp canines. They were good at riding and shooting. They fed on natural creatures and held awe and gratitude for this. Na'vi lived in a "home tree" that stretched through thousands of miles, and the numerous branches formed the world that Na'vi people lived in. They believed in Eywa, the mother of all things. She was the source of all life and the final place of soul after death. She was their spiritual belief and a prophet that can present indications.

Na'vi people were full of piety and awe in everything around them. When they had to kill an animal, they would quickly end its life to reduce its suffering and prayed that it would return to the goddess Eywa. Their braids were the "connector" for them to communicate with animals and plants. Neytiri once taught Jake to communicate with the soul tree and Icaran (dragons) with her braids. What Neytiri always emphasized to Jake was "I see you", refers to the communication with animals, plants and the natural world by heart and soul.

At this time, Earth was a ruin destroyed place and also a den of iniquity. Pandora was the last hope of earthmen, a place of happiness, purity and beauty.

\section{Betrayal -- Reconciliation -- Conversions: the Rebirth of Jake}

It was out of selfishness that Jake first approached the Na'vi, because the Colonel had promised that he would give Jake a healthy leg if he could persuade the Na'vi people to move away from the place where their generations lived. However, Jake's original offish and cynical inner heart undergone tremendous changes in the process that he was accepted by the Na'vi. Jake who had been accustomed to the wildness and freedom of life in Na'vi's body was annoyed by the trapped deformity of the body: "Now everything is confused. What is on Pandora is true. I don't even know who I am."

The Colonel claimed that Jake "betrayed" mankind while he was condemned by Na'vi people and Neytiri after frankly telling them his identity. And then Jake was exiled by both parties at the same time. The U.S. military bombed the home tree and the Na'vi lost their home. Jake conquered the divine bird and turned himself into a brave Na'vi warrior. He led several clansmen responding to the U.S. military. At the end of the film, after successfully recapturing the land of Na'vi, Jake completed his rebirth under the tree of the soul, with the admission of Eywa. The word "Avatar" is derived from Sanskrit and refers to "God's incarnation on the earth". Finally, Jake played the role of the savior of Na'vi when the Na'vi people fought against earthmen. It is believed by some people that Avatar is "a metaphor of Cameron: It is hoped that mankind possesses both a modern technological mind and an ancient soul.'[6] The last conversion of Jake was the change from the values of anthropocentrism to the harmonious coexistence of all things and the unity of man and nature.

\section{Pandora Planet: "Star Colony" of America}

The attitude of the U.S. military to Na'vi people in Avatar reminds many viewers of the history of western capitalist countries' overseas colonization. When the capitalist countries are colonizing the world, they often implement obscurantist policies and cruel persecution at the same time. The same applies to colonization in Avatar. When Grace first arrived in Pandora, she set up a local school to 
teach Na'vi English. Although Grace was very kind, she regarded American culture as a powerful culture superior to Na'vi's and held that Americans "must" assume the responsibility of educating Na'vi people. This can be attributed to the American consciousness of great-power centralism. Americans equate their culture and civilization with the culture and civilization of the world and impose their own values on the world.

Althusser proposed "the ideological state machine", arguing that it convinces people of the rationality and scientificity of the established social order and civilization by influencing them through religion, ethics, morality, etc. Under this subtle influence, they regard their own culture as the proper civilization and intend to "benefit" other ethnic groups. The powerful culture represented by the United States seeks identity and universality. Conflicts naturally arise when this so-called powerful culture encounters other cultures. In Avatar, the "weak culture" represented by the Na'vi defeated the powerful culture of the United States. Director Cameron is to awaken all human beings: the future of mankind lies in the diversity of culture and the harmonious coexistence of man and nature.

\section{The Simple and Energy-Flowing Pandora: Complaints Against Anthropocentrism and Instrumental Rationality}

"Ethics" is often used to refer to the human-centered circle of civilization and refers to the norms of human behavior. This position is suspected of "anthropocentrism". The extension of "ethics" can be extended to the relationship between humans and nature and between humans and creatures. The thought of "reverent for life" by the French philosopher Albert Schweitzer is very revealing, "He extended the scope of ethics to animals and plants, and he believed that awe should be shown to not only the life of human beings but also the life of all creatures" [7].

The deterioration of the relationship between people and nature on Earth is largely due to the deviation of human values. The place in which Na'vi people had lived for generations was their roots and lifeblood. Without Pandora, there would be no Na'vi, so they must defend their homeland. This is not only the fulfillment of obligations but also a natural expression. For the Earthmen, Pandora is just a new type of huge mine field, and what they can see is only the huge economic benefits.

All of Pandora's creatures are larger than that on earth, which is of course the result of the author's exaggerated imagination. All the creatures on Pandora are similar to those on Earth. Pandora is the projection of the earth and the Na'vi can be regarded as another kind of human being on Earth. What is different is that, the Na'vi people and the forest had formed an "energy network" when the Earthmen separated themselves from nature. The Na'vi people recognized the mutual flow of energy between all things, which brought boundless vitality to the Na'vi people and Pandora.

Pandora was a symbol of hope and also the last paradise in the galaxy. All the creatures on Pandora are equal, and there is neither lowliness nor nobleness .On Pandora, man is an integral part of nature and everything is harmonious and natural. Pandora has a variety of strange creatures, but no war conquest and no killing. All Na'vi people follow the laws of the natural world and what they strive for is conforming to nature and conforming to natural instincts. Eywa has a similar pronunciation with the word "Eve (the mother of mankind)". Eywa was the goddess of the Na'vi, the mother of all things, the source of life and the spiritual pillar of Na'vi people. When the Na'vi people were in disaster, when they were in pain or when they were confused, they would all pray at the feet of Eywa. Eywa was regarded as a female. She was a goddess and the mother of the earth on Pandora.

Trees are a symbol of hometown and homeland for the Chinese people. The home tree of Na'vi stretched for thousands of miles and they gave birth to and raised children there. This was place where they sheltered from wind and rain and where their souls were solaced. This is why they desperately cried and shed bitter tears after the home tree was destructed. 


\section{Conclusion}

Marx pointed out: "The victory of technology seems to come at the cost of moral corruption. With the increasing control of nature by mankind, individuals seem to increasingly become slaves to other people or slaves to their own despicable behavior." [8] Regardless of the direction in which literary studies have or will develop, the expression of human ethics is a topic that will never be out of date. The values of anthropocentrism were pushed from the earth to the planet Pandora, while the plundering of nature was extended from the earth to here. Although this is a story on the planet Pandora, it refers to the earth. The film warns us that the values and ethics of anthropocentrism are urgently needed to be changed.

\section{References}

[1]. Zhao Qing. Interpreting the Movie Avatar Based on Taoist Thoughts [J]. Anhui Literature $<$ ANHUI WENXUE $>$, 2011(2).

[2]. Cui Jingjing. Ecological Ethics in the Film Avatar [J]. Short Story, 2012 (4).

[3]. Karl Marx and Frederick Engels (Volume 12) [M]. Beijing: People's Publishing House, 1965.

[4]. Zhao Lili. Harmony and Regression in Avatar [J]. Journal of Henan Institute of Science and Technology, 2012(11).

[5]. Guan Fenfen, Liao Lili. Interpretation of Avatar from the Perspective of Ethical Literary Criticism [J]. Movie Literature, 2010(19)

[6]. http://baike.baidu.com/link?url=X9evdudtfPXeHq2_2O8waMJ10LaGfi6i3dYdBmwMNq16fp WAvG3Lc9WcNA6YCC5aFMxN4T9ulX40bEjQIBQW_30i02blE8mOPVLEIO1ViFO6iNY gmBslFIdbaUheCwUAn19erIq17C21nXt5NKPea

[7]. 2Cui Jingjing. Ecological Ethics in the Film Avatar. Short Story, 2012 (4)

[8]. Karl Marx and Frederick Engels (Volume 1) (P. 176). Beijing: People's Press 